\title{
Laser cladding of martensitic stainless steels on armor steels
}

\section{Ekrem Altuncu}

Department of Metallurgical and Materials Engineering, Faculty of Technology, Sakarya University of Applied Sciences, Sakarya, Turkey (corresponding author: altuncu@subu.edu.tr) (Orcid:0000-0002-1395-9013)

\section{Melih Tarım}

Department of Metallurgical and Materials Engineering, Faculty of Technology, Sakarya University of Applied Sciences, Sakarya, Turkey

Armor steels in the defense industry are widely used in ballistic applications due to their high mechanical strength and toughness. Problems caused by wear and in service conditions have limited the life of these steels. In recent years, the laser cladding method is one of the preferred hard-facing method. Laser powder cladding is a widely used process for improving the surface and near-surface properties of a metallic part or to resurface a component that has become worn through use. Cladding involves the creation of a hard surface layer on substrate. Compared with welding methods, cladding offer lower heat-related distortion, reduced dilution, extremely low porosity and better surface uniformity. In this study, martensitic stainless steel powders were deposited using the laser cladding method to improve the surface resistance of armor steel. In experimental studies, the effects of process parameters (laser power, laser speed and powder feed rate) on the layer were investigated. The microstructure and dilution properties of the cladding layers were examined. It was determined that the cladding layer structure had a high hardness and a low dilution, as well as a completely martensitic phase. Increased surface resistance with laser cladding increased both the service life and wear resistance of armor steel.

\section{Introduction}

Armor steels are special alloys that combine the mechanical strength and toughness properties used in ballistic applications. ${ }^{1}$ Protection of the surface of the armor steel against atmospheric corrosion and under wear conditions improves its service life and performance. Crack formation under variable stress loads starts on the metal surface, and surface resistance can be increased with hard protective coatings. With thermal spray-coating methods, fatigue crack propagation can be delayed on metallic parts. However, the non-metallurgical adhesion strength of the coating limits the coating life. ${ }^{2}$ The most important feature of the laser cladding process is the high adhesion strength. Laser cladding of martensitic stainless steel offers distinct advantages, including low dilution, low heat input, less distortion, improved mechanical and corrosion properties and excellent repeatability and control of process parameters. ${ }^{3-5}$ The laser cladding process quality varies depending on the properties of powder and substrate and the variety of process parameters, such as laser power, powder feed rate, spray distance and scan speed. These parameters need to be controlled during the process. ${ }^{6-8}$ In this experimental study, the effects of laser cladding process parameters on the martensitic stainless steel cladding layer were investigated in order to improve the surface resistance of armor steel.

\section{Experimental procedures}

Laser cladding has been proven an ideal coating method for producing wear-resistant layers on industrial metallic components. In experimental studies, robotically controlled laser cladding (Erlas; neodymium (Nd)-doped yttrium (Y) aluminum (Al) garnet laser $2.2 \mathrm{~kW}$ ) was performed on martensitic chromium $(\mathrm{Cr})$ stainless steel powders (Metco 42C; $0 \cdot 18 \%$ carbon (C), 17\% chromium, 2\% nickel (Ni)) (Figure 1; particle size range: $-106+$ $45 \mu \mathrm{m}$, water-atomized, irregularly shaped). In the powder size distribution analysis results, the average powder size $\left(D_{50}\right)$ was $89 \cdot 70 \mu \mathrm{m}$. Metco $42 \mathrm{C}$ produces coatings that combine good wear resistance and impact strength with the best corrosion resistance of any martensitic stainless steel. A coaxial powder-feeding system was used to convey the powders, and a six-axis robot system was selected to control the movement of the laser head and the nozzle (Figure 2). Inert argon (Ar) gas was used to carry the powders and protect the molten pool. Laser cladding was performed on $6 \mathrm{~mm}$ flat plate armor steel substrate (Armox 500T; wt.\%: $0 \cdot 32$ carbon, $0 \cdot 4$ sulfur (S), 1.2 manganese (Mn), >1 NiCr). Armox 500T steels (tensile strength: $1500-1750 \mathrm{MPa}$; elongation: $8-10 \%$, impact resistance: $32 \mathrm{~J} /-40^{\circ} \mathrm{C}$ ) are plate products that combine good ballistic properties with excellent toughness. In this experimental study, the effects of different laser cladding process parameters (Table 1) on the cladding layer were investigated. The microstructure of the clad coating was examined under an electron microscope (scanning electron microcopy (SEM)-energydispersive X-ray spectroscopy); the dilution rate was calculated using image analysis. The microhardness of the cladding was taken from different regions by using a Vickers indenter $(300 \mathrm{~g}$, $15 \mathrm{~s}$ ), and the hardness profile was obtained. A corrosion test was carried out according to the ASTM B 117-18 standard. ${ }^{9}$

\section{Results and discussions}

\subsection{Cladding layer microstructure}

Figure 3 shows the microstructure of the laser coating near the coating/substrate interface, as well as details of the microstructure in the middle of the coating. The cross-sectional $42 \mathrm{C}$ martensitic 


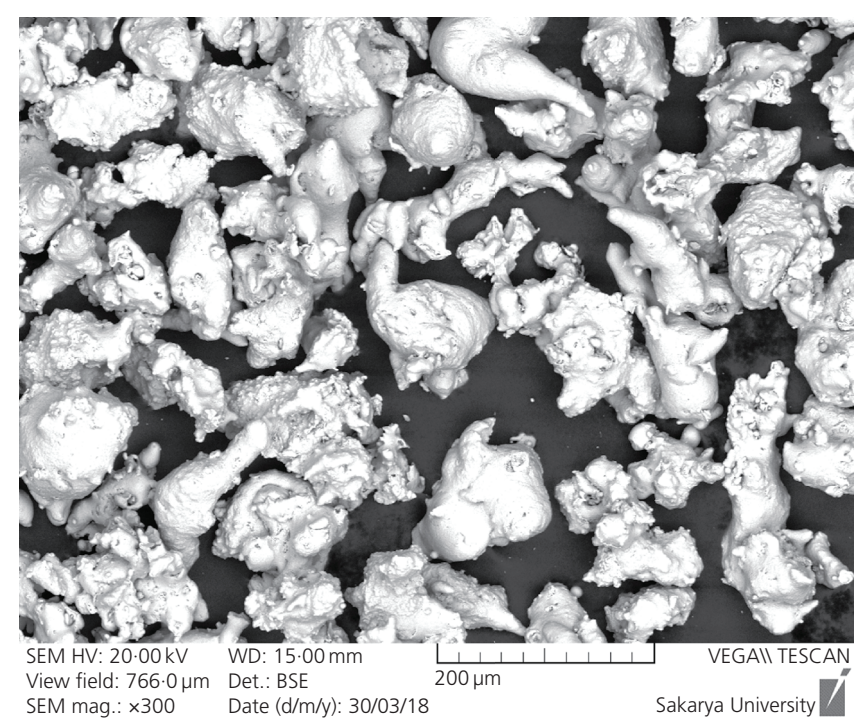

(a)

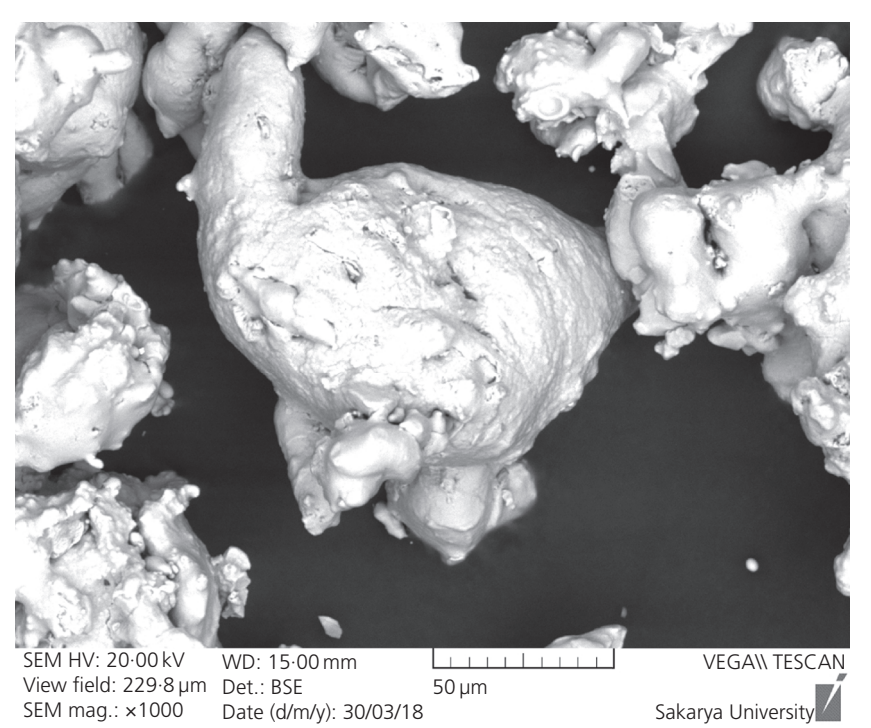

(b)

Figure 1. SEM micrograph of the laser cladding powders and powder morphology

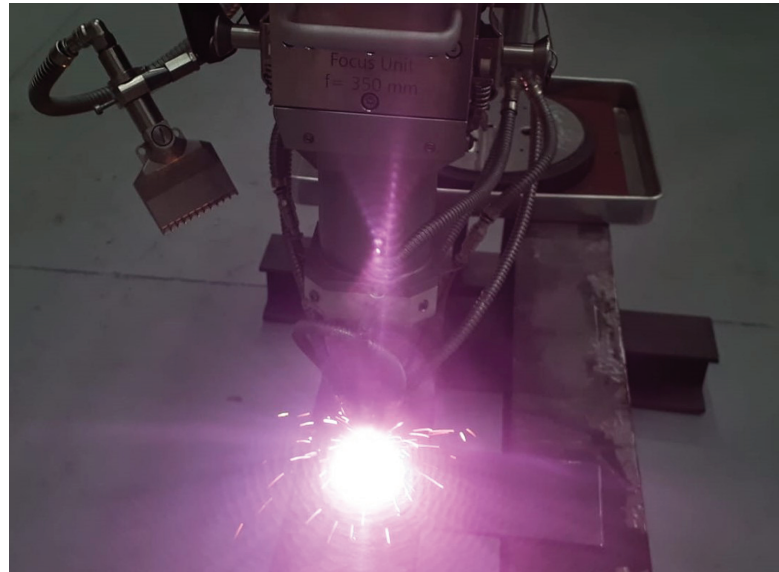

(a)

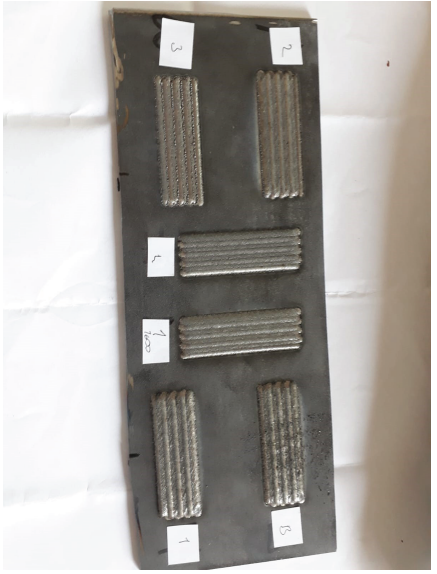

(b)

Figure 2. Laser cladding application and samples

stainless steel cladding layer showed no microcracking with a good fusion bond. As a result of optimized process parameters, the cladding layer had a completely martensitic structure. With increasing cooling rate, the characteristic microstructure size

Table 1. Laser cladding process parameters

\begin{tabular}{lc} 
Process parameter & Value \\
\hline Laser power: $W$ & $800-2000$ \\
Powder feed rate: $\mathrm{g} / \mathrm{min}$ & $1-15$ \\
Shield gas & Argon \\
Scan speed: $\mathrm{mm} / \mathrm{min}$ & $100-2000$ \\
Nozzle diameter: $\mathrm{mm}$ & 6 \\
Spray distance: $\mathrm{mm}$ & 12 \\
Shield gas pressure: bar & 3
\end{tabular}

decreased and the interdendritic phases became more refined for all layers.

\subsection{Dilution of the cladding layer}

Laser cladding requires the achievement of a strong fusion bond between the cladding material and the substrate, which, in turn, requires the formation of a melt pool in the substrate. It has to be noted, however, that the depth of this melt must be as small as possible in order to obtain a pure surface layer that is not diluted by the base material. The dilution is defined as the ratio of the clad depth $\left(D_{\mathrm{c}}\right)$ in the substrate over the total clad height $\left(T_{\mathrm{c}}\right)$. Dilution increases with increasing power and decreases with increasing powder feed rate. Table 2 shows the dilution ratio change due to laser cladding parametric experiments. 


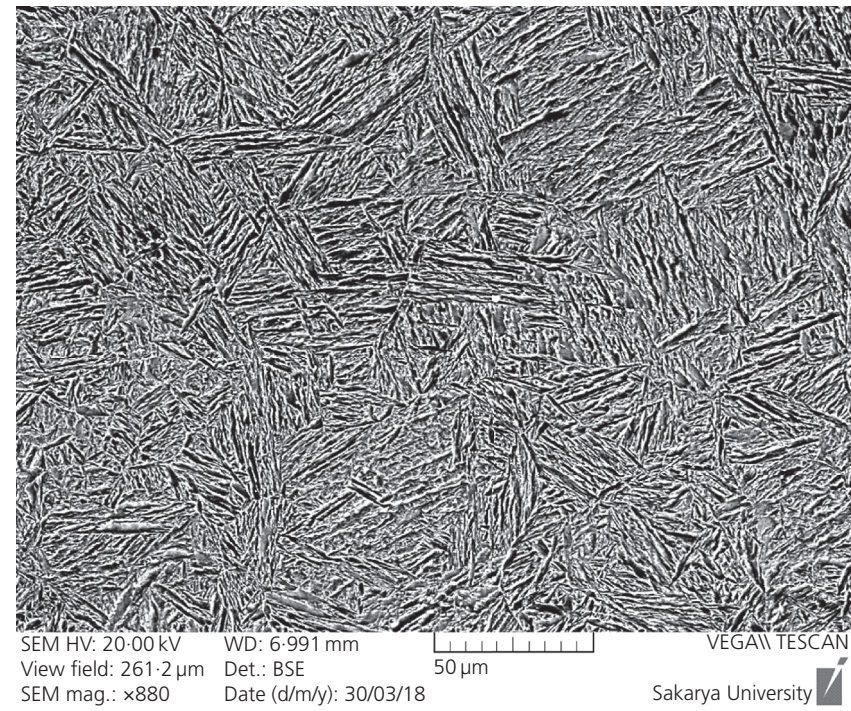

(a)

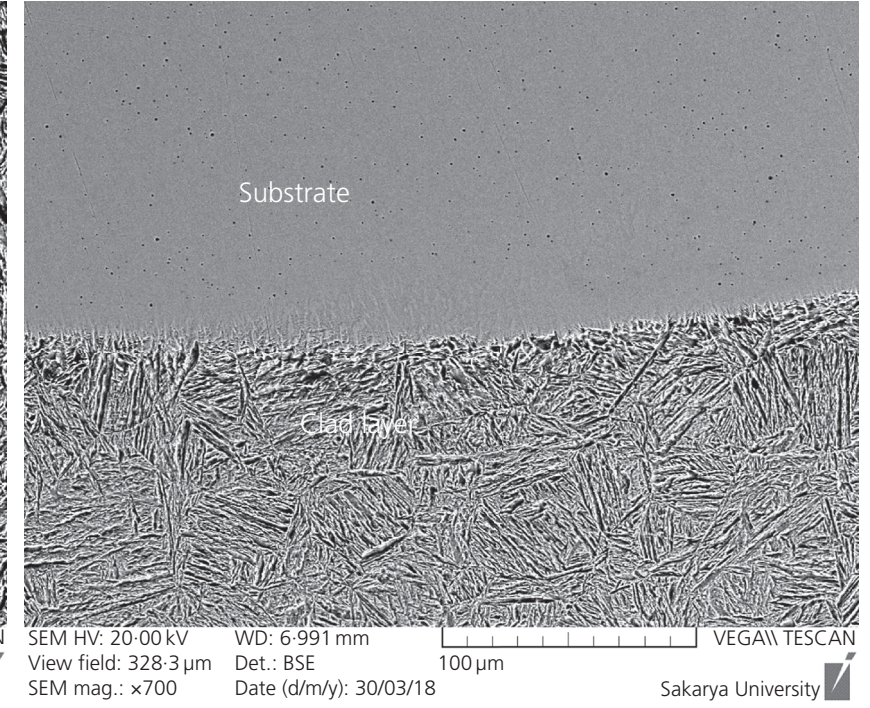

(b)

Figure 3. SEM microstructures of the cladding layer and interface

Table 2. Dilution ratios of the laser cladding experiments

High laser power

$45 \%$

Medium laser power

$22 \%$

Optimum laser power

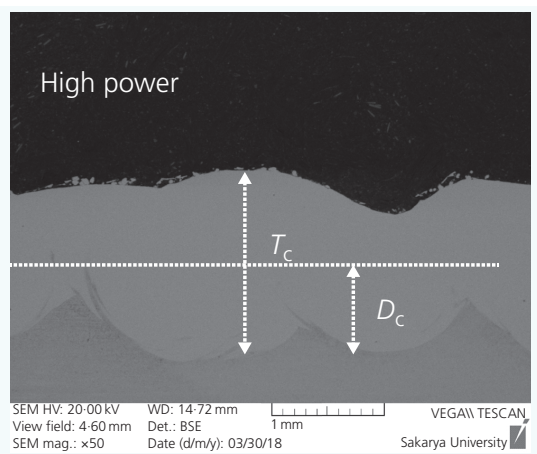

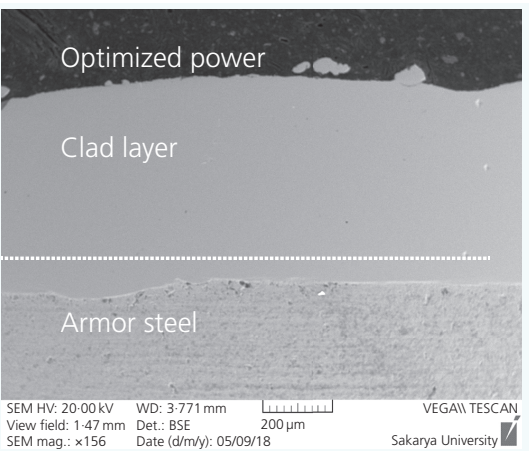

\subsection{Microhardness profile}

Hardness, as an important characteristic that influences wear performance, was measured to quantify the quality of the clad coatings. Figure 4 shows the depth profile of Vickers hardness measured through the cross-section of the laser cladding on the armor steel substrate. The microhardness of the cladding layer and bonding surface was higher than that of the substrate. The substrate hardness was $400 \pm 20 \mathrm{HV} 0 \cdot 3$ on average. Microhardness of cladding layer was about $620 \pm 50 \mathrm{HV} 0 \cdot 3$, and this value is too higher than the substrate metal. This is owing to the presence of a hard phase in the cladding layers. The microhardness variation with the increasing plasma power was examined (800-2000 W) were examined, the lowest hardness $(510 \pm 15 \mathrm{HV} 0 \cdot 3)$ of the cladded layers was obtained at the lowest plasma power $(800 \mathrm{~W})$ and the highest hardness values $(650 \pm$ $20 \mathrm{HV} 0 \cdot 3$ ) were obtained at $1200 \mathrm{~W}$ (constant scan speed $200 \mathrm{~mm} /$ $\mathrm{min}$; feed rate: $6 \mathrm{~g} / \mathrm{min}$; pressure: 3 bar). The microstructural properties of the cladding layer depend on the laser power; when the laser power is low, the powder cannot be melted properly, so microcracks will develop, and if the laser power is high, then the problems of overheating, changes in the microstructure and high dilution can be encountered, which can decrease the surface resistance. The scanning speed of the laser cladding process is a more significant parameter for obtaining a good-quality cladding layer. The height, width and thickness of the cladding layer depend on the scanning speed. When the scanning speed is appropriate, then the cladding layer has better properties, such as no cracks and gas porosity and good metallurgical bonding with the base material. The cladding thickness depends on the feed rate. Coating thickness is directly proportional to the powder feed rate.

\section{General conclusions}

This research investigated the relationship between different process parameters and the hardness and dilution properties of laser cladding. The results showed evidence of the different characteristics of the laser cladding coatings using different laser powers and scan speeds on the surface. Martensitic stainless steel layers were deposited successfully on the surface of the armor steel by the laser cladding 


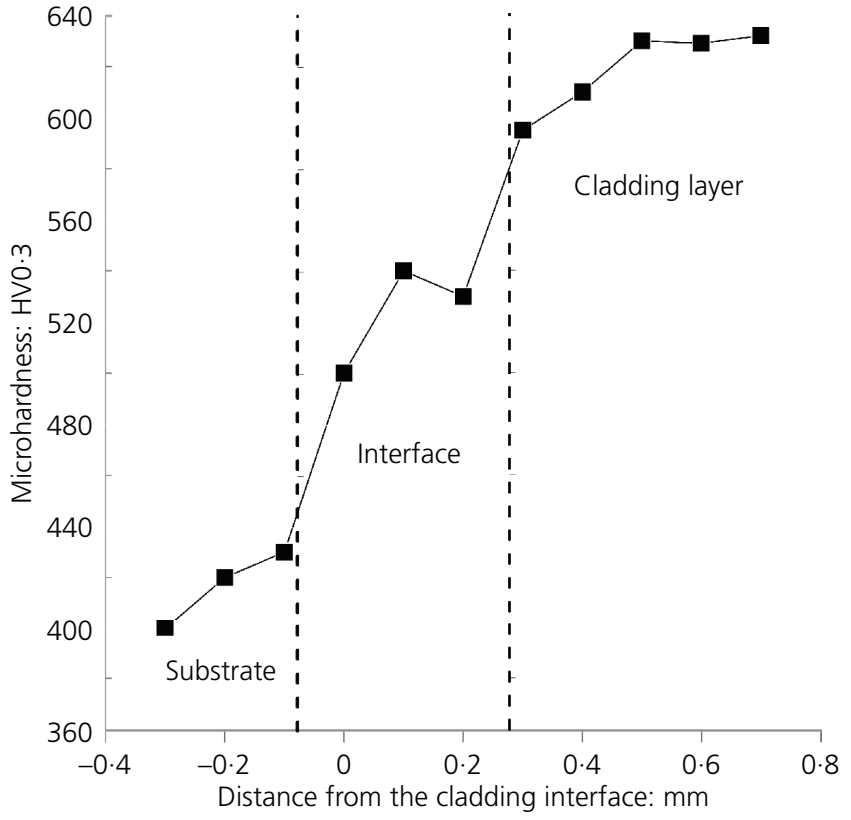

Figure 4. Microhardness profile of the optimized cladding layer

process. It was determined that the desired cladding layer could be produced without defects by optimizing the process parameters. Laser power has the primary effect on the width and depth of the cladding layer. The scanning speed has a significant effect on the cladding layer height. The optimum laser cladding process parameters obtained in this experimental study were $1200 \mathrm{~W}$ plasma power, 3 bar gas pressure, $6 \mathrm{~g} / \mathrm{min}$ powder feed rate and $200 \mathrm{~mm} / \mathrm{min}$ scanning speed. Laser cladding is a highly controllable/repeatable and efficient hard-facing process. The results can be used as a guideline for the selection of proper processing parameters for laser cladding. The increased surface resistance of armor steel obtained using the laser cladding method increased both its service life and wear resistance. Laser-cladded armor steels have 2.5 times higher corrosion resistance than uncoated ones. No corrosion was observed on cladded surfaces for $240 \mathrm{~h}$.

\section{Acknowledgement}

The authors would like to thank UniqueTech Engineering Company, Gebze, Turkey, for their support in cladding experimental work.

\section{REFERENCES}

1. Hu CJ, Lee PY and Chen JS (2002) Ballistic performance and microstructure of modified rolled homogeneous armor steel. Journal of the Chinese Institute of Engineers 25: 99-107.

2. Altuncu E and Iriç S (2017) Evaluation of fracture toughness of thermal sprayed and hard chrome coated aluminium-zinc alloy. Acta Physica Polonica A 132(3-II): 926-929.

3. More SR, Bhatt DV and Menghani JV (2017) Resent research status on laser cladding as erosion resistance technique - an overview. Materials Today: Proceedings 4(9): 9902-9908.

4. Xu M, Li J, Jiang J and Li B (2015) Influence of powders and process parameters on bonding shear strength and micro hardness in laser cladding remanufacturing. Procedia CIRP 29: 804-809.

5. Navas C, Conde A, Fernández BJ, Zubiri F and De Damborenea J (2005) Laser coatings to improve wear resistance of mould steel. Surface and Coatings Technology 194: 136-142.

6. Bax B, Rajput R, Kellet R and Reisacher M (2018) Systematic evaluation of process parameter maps for laser cladding and directed energy deposition. Additive Manufacturing 21: 487-494.

7. Reddy L, Preston SP, Shipway PH, Davis C and Hussain T (2018) Process parameter optimisation of laser clad iron based alloy: predictive models of deposition efficiency, porosity and dilution. Surface and Coatings Technology 349: 198-207.

8. Hemmati I, Ocelík V and De Hosson JTM (2011) The effect of cladding speed on phase constitution and properties of AISI 431 stainless steel laser deposited coatings. Surface and Coatings Technology 205: 5235-5239.

9. ASTM (2018) B 117-18: Standard practice for operating salt spray (fog) apparatus. ASTM International, West Conshohocken, PA, USA.

\section{How can you contribute?}

To discuss this paper, please submit up to 500 words to the journal office at journals@ice.org.uk. Your contribution will be forwarded to the author(s) for a reply and, if considered appropriate by the editor-in-chief, it will be published as a discussion in a future issue of the journal.

ICE Science journals rely entirely on contributions from the field of materials science and engineering. Information about how to submit your paper online is available at www.icevirtuallibrary.com/page/authors, where you will also find detailed author guidelines. 